Check for updates

Cite this: Sustainable Energy Fuels, 2019, 3, 1682

Received 27th November 2018 Accepted 14th May 2019

DOI: $10.1039 / \mathrm{c} 8 \mathrm{se} 00579 f$

rsc.li/sustainable-energy

\section{Radiation-grafted cation-exchange membranes: an initial ex situ feasibility study into their potential use in reverse electrodialysis $\uparrow:$}

\author{
Terry R. Willson, (D) *a Ian Hamerton, (iD ab John R. Varcoe (iD a and Rachida Bance- \\ Soualhi iD a
}

\begin{abstract}
A variety of radiation-grafted cation-exchange membranes (RG-CEM) were synthesised, using a high-dose rate electron-beam peroxidation method, for an initial evaluation of their applicability to reverse electrodialysis cells (RED, a type of salinity gradient "blue" energy). The RG-CEMs were adequately conductive (to $\mathrm{Na}^{+}$cations) but without the incorporation of crosslinking co-monomers, the permselectivities were too low ( $\leq 80 \%$ ). In contrast, when ETFE-based RG-CEMs were synthesised with incorporation of $10 \% \mathrm{~mol}$ bis(vinylphenyl)ethane (BVPE) crosslinking co-monomer into the styrenecontaining grafting mixture, permselectivities of $>90 \%$ were obtained without a significant decrease in conductivity. The use of BVPE in the grafting mixture also resulted in the RG-CEMs exhibiting enhanced ion-exchange capacities without any increase in water uptakes (cf. uncrosslinked variants). In contrast, the use of less flexible divinylbenzene crosslinker led to prohibitively large decreases in RG-CEM conductivity. This study highlights that the future development of both radiation-grafted cationexchange and anion-exchange membranes for RED (and other electrodialysis applications) should utilise flexible crosslinkers (such as BVPE) to ensure adequate permselectivities.
\end{abstract}

\section{Introduction}

Reverse electrodialysis (RED) is a major type of salinity gradient power technology. ${ }^{\mathbf{1}}$ RED cells directly generate electricity from the difference in salinities of feedwaters (ultimately from natural waters and/or wastewaters). They require the use of both cation- and anion-exchange membranes. ${ }^{2}$ Two primary ionexchange membrane (IEM) factors that affect the electrochemical performance of RED cells are area specific resistance (ASR) and permselectivity $(\alpha){ }^{3}$ low ASR and high $\alpha$ values are required for high power outputs. Other IEM factors that impact both short-term and long-term in situ performances are monovalent ion selectivity and fouling resistance. ${ }^{4}$

Radiation-grafting is a method that has been used to produce IEMs for many electrochemical technologies including

\footnotetext{
a Department of Chemistry, The University of Surrey, Guildford, GU2 7XH, UK. E-mail: t.willson@outlook.com

${ }^{b}$ Bristol Composites Institute (ACCIS), Department of Aerospace Engineering, School of Civil, Aerospace, and Mechanical Engineering, University of Bristol, Queen's Building, University Walk, Bristol, BS8 1TR, UK

$\dagger$ Raw data in support of this article is feely available (CC-BY) from DOI: 10.15126/surreydata.8124686

\$ Electronic supplementary information (ESI) available: Description of the synthesis and characterisation of the BVPE crosslinker; Raman and solid-state ${ }^{13} \mathrm{C}$ NMR of all the RG-CEMs mentioned in Tables 1-3; additional property correlation data for all RG-CEMs synthesised for this study. See DOI: 10.1039/c8se00579f
}

fuel cells and redox flow batteries. ${ }^{5}$ It involves the irradiation of polymer films with either $\gamma$-rays or electron-beams. This "activates" the films by introducing radicals and/or peroxide groups into them, which can then initiate copolymerisation of a range of vinyl monomers to form graft copolymer membranes. These grafts can then be further modified (e.g. sulfonated) as required. To date, radiation-grafted IEMs have not been specifically studied with their application in RED cells in mind.

\section{Scope of this study}

As radiation-grafted IEMs may be amenable for use in RED cells, an initial ex situ study focused on radiation-grafted cationexchange membranes (RG-CEMs) was conducted. Several crosslinked and non-crosslinked RG-CEM variants were synthesised and compared: (1) partially fluorinated poly(vinylidene fluoride) (PVDF) and poly(ethylene-co-tetrafluoroethylene) (ETFE) were used as the precursor films; (2) styrene and 4-vinylbenzene sodium sulfonate (VBS) were chosen as the monomers for the introduction of the sulfonate (cation-exchange) sites into the membranes (styrene grafting requires a two-step process, grafting and sulfonation, whilst VBS only requires a one-step process, grafting); (3) divinylbenzene (DVB) and bis(vinylphenyl)ethane (BVPE) were investigated as crosslinking co-monomers (yielding rigid and flexible crosslinks, respectively). The aim was to study the effect that different RG-CEM syntheses had on $\alpha$ values (such that $\alpha$ values were maximised, i.e. $>90 \%$ ), whilst avoiding any 
relative decreases in RG-CEM conductivity (increases in resistances). A future study is planned which will evaluate the RGCEMs (alongside radiation-grafted anion-exchange membranes) in salt solutions and RED cells.

\section{Materials and methods}

The poly(vinylidene fluoride) (PVDF) and poly(ethylene-co-tetrafluoroethylene) (ETFE) precursor films, both $50 \mu \mathrm{m}$ thick, were supplied by Nowofol (Germany). The vinyl monomers, 4-vinylbenzene sodium sulfonate (technical, $\geq 90 \%$ ) and styrene (ReagentPlus ${ }^{\circledR}, \geq 99 \%$, containing 4-tert-butylcatechol inhibitor), as well as the crosslinking monomer divinylbenzene (DVB, technical grade, $80 \%$, mixture of meta- and para-isomers, containing 1000 ppm 4-tert-butylcatechol as inhibitor) were purchased from Sigma-Aldrich and used without any further purification or removal of inhibitors. $\mathrm{NaCl}$ (BioXtra, $\geq 99.5 \%$, used to make the $\mathrm{NaCl}$ aqueous ion-exchange solutions), dichloromethane ( $\geq 99.9 \%$ ), and chlorosulfonic acid $\left(\mathrm{ClSO}_{3} \mathrm{H}, 99 \%\right)$ were supplied by Sigma-Aldrich and used as received. Toluene (low in sulphur) and $\mathrm{H}_{2} \mathrm{SO}_{4}$ (certified ACS Plus, 98\%, used to prepare the aqueous $\mathrm{H}_{2} \mathrm{SO}_{4}$ solutions) were purchased from Fisher Scientific and used as received. Aqueous analytical solutions were prepared using ultra-pure deionised water (UPW, resistivity $=18.2 \mathrm{M} \Omega \mathrm{cm}$ ).

\section{Pre-irradiation (peroxidation) of the polymer films}

The PVDF and ETFE films were cut to an area of $120 \mathrm{~mm} \times 120$ $\mathrm{mm}$, and up to 10 films were then placed into sealable polythene bags (containing air - no inert gas filling was used). Films were then subjected to radiation absorbed doses up to $70 \mathrm{kGy}( \pm 10 \%)$ via $10 \mathrm{kGy}$ dose per pass through a $5 \mathrm{MeV}$ electron-beam (Synergy Health Sterilisation UK Ltd., Swindon). The actual absorbed doses used are presented in Tables 1-3 (see later). Immediately after irradiation, the polymer films were stored in solid $\mathrm{CO}_{2}$ for transportation (ca. $1.5 \mathrm{~h}$ duration) before being transferred to a $-40{ }^{\circ} \mathrm{C}$ cold storage freezer immediately on arrival at the laboratory.

\section{Grafting of styrene to the polymer films with subsequent sulfonation (without the use of crosslinking co-monomers)}

Styrene was grafted into the PVDF and ETFE films via an adaption of a previously reported method. ${ }^{6}$ An outline of the process is presented in Scheme 1. A styrene : toluene grafting solution (2:3 vol ratio) was prepared in a large glass vessel (cylindrical with a round bottom and ground glass flanged lid containing ground glass ports). The pre-irradiated films were removed from the freezer, rolled between sheets of single-ply tissue paper, and submerged in the grafting solution. The grafting vessel was then sealed, purged with low pressure $\mathrm{N}_{2}$ for $1 \mathrm{~h}$, and then heated to $70{ }^{\circ} \mathrm{C}$ for $72 \mathrm{~h}$. On completion, the PVDFand ETFE- $g$-polystyrene grafted membranes were washed with toluene and dried in a vacuum oven at $70{ }^{\circ} \mathrm{C}$ for $5 \mathrm{~h}$.

For the sulfonation step, ${ }^{6}$ the polystyrene-grafted membranes were placed into a dichloromethane solution of $\mathrm{ClSO}_{3} \mathrm{H}(5 \% \mathrm{vol})$ at ambient temperature for $2 \mathrm{~h}$. After quenching via immersion into a large volume of deionised water, the crude sulfonated membranes were then washed
Table 1 The synthesis conditions and key properties for three exemplar RG-CEMs synthesised without the addition of divinyl-type crosslinking agents into the grafting mixtures. All measurements were conducted on the $\mathrm{Na}^{+}$form RG-CEMs (except for IEC). Errors are from measurements on $n=4$ samples of RG-CEM ( $n=3$ for ion conductivity measurements)

\begin{tabular}{llll}
\hline & PS-0 & PV-0 & ES-0 \\
\hline Base material $^{a}$ & PVDF & PVDF & ETFE \\
Radiation dose/kGy & 30 & 70 & 30 \\
Monomer & Styrene & VBS $^{b}$ & Styrene \\
[Monomer] & $40 \% \mathrm{vol}^{c}$ & $1 \mathrm{~mol} \mathrm{dm}^{-3 d}$ & $40 \% \mathrm{vol}^{c}$ \\
Grafting temp. $/{ }^{\circ} \mathrm{C}$ & 70 & 60 & 70 \\
$\mathrm{Graft} \mathrm{time}^{c} \mathrm{~h}$ & 72 & 48 & 72 \\
[ClSO $\left._{3} \mathrm{H}\right]^{e}$ & $5 \% \mathrm{vol}$ & - & $5 \% \mathrm{vol}$ \\
$\mathrm{IEC} / \mathrm{mmol} \mathrm{g}^{-1 f}$ & $2.60 \pm 0.02$ & $2.31 \pm 0.02$ & $2.46 \pm 0.03$ \\
$\sigma_{\mathrm{Na}} / \mathrm{mS} \mathrm{cm}^{-1 g}$ & $27 \pm 2$ & $25 \pm 3$ & $27 \pm 4$ \\
$\mathrm{WU}(\%)^{h}$ & $50 \pm 1$ & $50 \pm 1$ & $51 \pm 1$ \\
$t_{\mathrm{hyd}} / \mu \mathrm{m}^{i}$ & $99 \pm 2$ & $77 \pm 2$ & $105 \pm 2$ \\
$\alpha(\%)^{j}$ & 65 & 53 & 65
\end{tabular}

${ }^{a}$ All irradiated polymer films were purchased with thicknesses of 50 $\mu \mathrm{m} .{ }^{b} 4$-Vinylbenzene sodium sulfonate. ${ }^{c}$ Toluene grafting solution. ${ }^{d}$ VBS dispersed in DMF $: \mathrm{H}_{2} \mathrm{SO}_{4}\left(9: 1 \mathrm{vol}\right.$ ratio) mixture. ${ }^{e}$ Sulfonation conducted by immersion of the styrene-grafted films in DCM solutions of chlorosulfonic acid $\left(\mathrm{ClSO}_{3} \mathrm{H}\right)$ for $2 \mathrm{~h}$ at ambient temperatures and pressures. ${ }^{f}$ Measured using titration of the $\mathrm{H}^{+}$form RG-CEMs. ${ }^{g}$ Through-plane $\mathrm{Na}^{+}$conductivities in water at room temperature measured using our previously reported two-probe impedance spectroscopy method. ${ }^{10}{ }^{h}$ Gravimetric water uptakes. ${ }^{i}$ RGCEM thickness when fully hydrated. ${ }^{j}$ Permselectivity (target for $\alpha$ was set to $>90 \%$ for the purpose of this initial RG-CEM development study).

several times and boiled in UPW for $1 \mathrm{~h}$ to obtain the fully hydrated RG-CEMs (in $\mathrm{H}^{+}$forms). To obtain the $\mathrm{Na}^{+}$forms, the RG-CEMs were ion-exchanged via immersion in aqueous $\mathrm{NaCl}$ $\left(1.0 \mathrm{~mol} \mathrm{dm}^{-3}, 3 \times 30 \mathrm{~min}\right)$ followed by vigorous washing with UPW (to remove all excess co- and counter-ions). All RG-CEMs were stored in UPW until required.

Table 2 The synthesis conditions and key properties for three exemplar ETFE-based RG-CEMs with and without the addition of divinylbenzene (DVB) into the grafting mixtures. All measurements were conducted on the $\mathrm{Na}^{+}$form RG-CEMs (except for IEC). Errors are from measurements on $n=3$ samples of RG-CEM ( $n=4$ for the WU experiments)

\begin{tabular}{|c|c|c|c|}
\hline & ES-D0 & ES-D5 & ES-D10 \\
\hline Base material & \multicolumn{3}{|c|}{ ETFE $(50 \mu \mathrm{m}$ thick $)$} \\
\hline Radiation dose/kGy & 30 & & \\
\hline$[\mathrm{DVB}]^{a}$ & $0 \% \mathrm{~mol}$ & $5 \% \mathrm{~mol}$ & $10 \% \mathrm{~mol}$ \\
\hline Grafting temp. $/{ }^{\circ} \mathrm{C}$ & 70 & & \\
\hline Graft time/h & 8 & & \\
\hline$\left[\mathrm{ClSO}_{3} \mathrm{H}\right]^{b}$ & $5 \% \mathrm{vol}$ & & \\
\hline $\mathrm{IEC} / \mathrm{mmol} \mathrm{g}^{-1 c}$ & $1.88 \pm 0.02$ & $2.37 \pm 0.03$ & $1.92 \pm 0.01$ \\
\hline$\sigma_{\mathrm{Na}^{+}} / \mathrm{mS} \mathrm{cm}^{-1 c}$ & $15.0 \pm 4.6$ & $6.4 \pm 1.9$ & $4.1 \pm 2.4$ \\
\hline $\mathrm{WU}(\%)^{c}$ & $42 \pm 1$ & $21 \pm 2$ & $15 \pm 1$ \\
\hline$t_{\text {hyd }} / \mu \mathrm{m}^{c}$ & $91 \pm 2$ & $80 \pm 2$ & $71 \pm 2$ \\
\hline$\alpha(\%)^{c}$ & 80 & 74 & 97 \\
\hline
\end{tabular}

${ }^{a}$ Added to a grafting mixture containing styrene : toluene $(2: 3 \mathrm{vol}$ ratio). ${ }^{b}$ Sulfonation conducted by immersion of the styrene-grafted films in DCM solutions of $\mathrm{ClSO}_{3} \mathrm{H}$ for $2 \mathrm{~h}$ at ambient temperatures and pressures. ${ }^{c}$ For definitions for these properties, see the footnotes to Table 1. 
Table 3 The synthesis conditions and key properties for three exemplar ETFE-based RG-CEMs with and without the addition of bis(vinylphenyl)ethane (BVPE) into the grafting mixtures. All measurements were conducted on the $\mathrm{Na}^{+}$form RG-CEMs (except for IEC). Errors are from measurements on $n=3$ samples of RG-CEM ( $n=4$ for the WU experiments)

\begin{tabular}{|c|c|c|c|}
\hline & ES-B0 & ES-B5 & ES-B10 \\
\hline Base material & \multicolumn{3}{|c|}{ ETFE $(50 \mu \mathrm{m}$ thick $)$} \\
\hline Radiation dose/kGy & 30 & & \\
\hline$[\mathrm{BVPE}]^{a}$ & $0 \% \mathrm{~mol}$ & $5 \% \mathrm{~mol}$ & $10 \% \mathrm{~mol}$ \\
\hline Grafting temp. $/{ }^{\circ} \mathrm{C}$ & 70 & & \\
\hline Graft time/h & 8 & & \\
\hline$\left[\mathrm{ClSO}_{3} \mathrm{H}\right]^{b}$ & $5 \%$ vol & & \\
\hline $\mathrm{IEC} / \mathrm{mmol} \mathrm{g}^{-1 c}$ & $1.88 \pm 0.02$ & $2.86 \pm 0.13$ & $3.07 \pm 0.06$ \\
\hline$\sigma_{\mathrm{Na}^{+}} / \mathrm{mS} \mathrm{cm}^{-1 c}$ & $15.0 \pm 4.6$ & $26.9 \pm 5.2$ & $15.7 \pm 1.4$ \\
\hline WU $(\%)^{c}$ & $42 \pm 1$ & $50.6 \pm 0.2$ & $41 \pm 1$ \\
\hline$t_{\text {hyd }} / \mu \mathrm{m}^{c}$ & $91 \pm 2$ & $97 \pm 2$ & $91 \pm 2$ \\
\hline$\alpha(\%)^{c}$ & 80 & 83 & 92 \\
\hline
\end{tabular}

${ }^{a}$ Added to a grafting mixture containing styrene : toluene $(2: 3 \mathrm{vol}$ ratio). ${ }^{b}$ Sulfonation conducted by immersion of the styrene-grafted films in DCM solutions of $\mathrm{ClSO}_{3} \mathrm{H}$ for $2 \mathrm{~h}$ at ambient temperatures and pressures. ${ }^{c}$ For definitions for these properties, see the footnotes to Table 1.
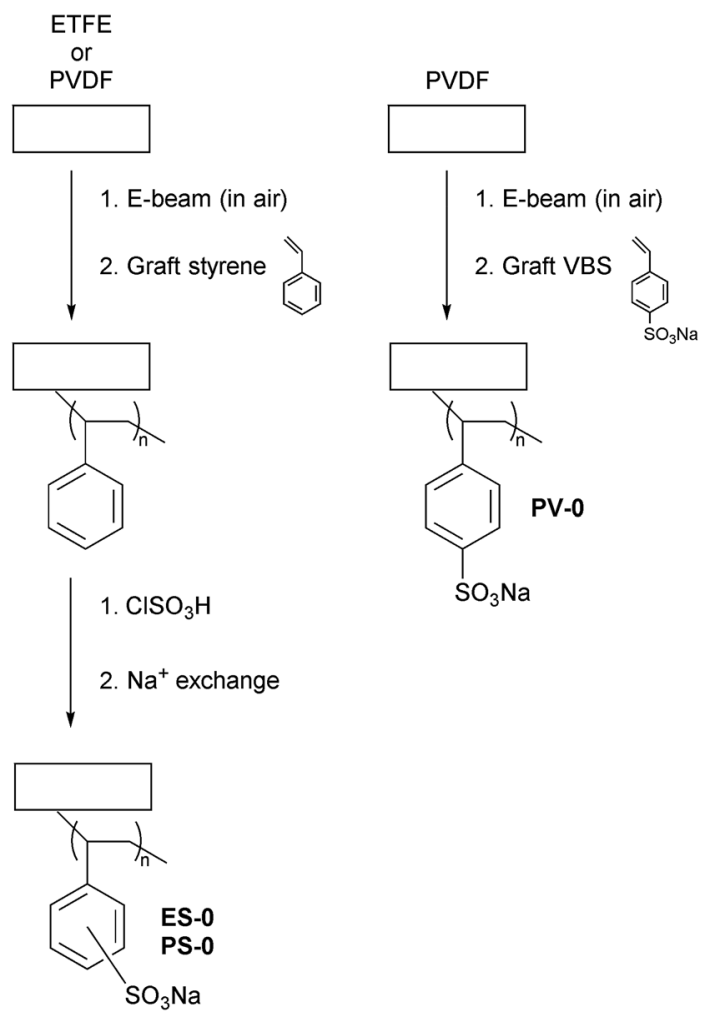

Scheme 1 An outline of the synthesis of the uncrosslinked RG-CEMs: PS-0, PV-0, and ES-0.

\section{Grafting of 4-vinylbenzene sodium sulfonate (VBS) to PVDF films}

Graft co-polymerisation of VBS into the PVDF film was based on the method reported by Nasef et $a l^{7}$ A grafting mixture consisting of VBS monomer $\left(1.0 \mathrm{~mol} \mathrm{dm}{ }^{-3}\right)$ in a $\mathrm{DMF} / \mathrm{H}_{2} \mathrm{SO}_{4}$ solution (DMF : $\mathrm{H}_{2} \mathrm{SO}_{4}=9: 1 \mathrm{vol}$ ratio) was prepared and decanted into a glass grafting vessel. The vessel was modified by fitting a perforated platform at its base to improve stirring and the homogeneity of the grafting mixture. The pre-irradiated PVDF films were removed from the freezer, rolled between sheets of single-ply tissue paper, and submerged in the grafting solution. The grafting vessel was then sealed, purged with low pressure $\mathrm{N}_{2}$ for $1 \mathrm{~h}$, and then heated to $60{ }^{\circ} \mathrm{C}$ for $48 \mathrm{~h}$. On completion, the resulting, crude RG-CEMs were washed several times in deionised water and placed in an ultra-sonic bath overnight to remove any excess or homopolymerised VBS monomer. The final RG-CEMs $\left(\mathrm{Na}^{+}\right.$form) were stored in UPW until required.

\section{Grafting of styrene and crosslinking co-monomers to the ETFE films with subsequent sulfonation}

The ETFE films were grafted with styrene in the presence of the additional divinyl-based crosslinking co-monomers: ${ }^{8}$ DVB (commercial) and bis(vinylphenyl)ethane (BVPE, see ESI for inhouse synthesis). Grafting solutions containing styrene : toluene, ( $2: 3 \mathrm{vol}$ ratio) were used with the addition of 0,5 or $10 \%$ mol crosslinking co-monomer in ground-glass boiling tubes $\left(80 \mathrm{~cm}^{3}\right)$. The pre-irradiated ETFE films (30 kGy absorbed dose) were rolled between single-ply tissue paper and submerged into each grafting solution. The reaction boiling tubes were then sealed, purged with $\mathrm{N}_{2}$ for $1 \mathrm{~h}$, and heated to $70{ }^{\circ} \mathrm{C}$ for $8 \mathrm{~h}$. On completion, the grafted membranes were washed with toluene and dried in a vacuum oven at $70{ }^{\circ} \mathrm{C}$ for $5 \mathrm{~h}$. The subsequent sulfonation and ion-exchange procedures were exactly as described above. An outline of the crosslinks that can form is presented in Scheme 2.

\section{Spectroscopic characterisation of the RG-CEMs}

Raman spectra were obtained using either a Thermo Scientific DXR Raman Microscope (equipped with either a $780 \mathrm{~nm}$ (IR) laser or a $532 \mathrm{~nm}$ green laser) or a Renishaw InVia Reflex Raman Microscope (equipped with an $785 \mathrm{~nm}$ IR laser): see figure captions for the laser wavelengths used to collect each spectrum. Raman cross-sectional maps were collected with the InVia Raman Microscope using the $785 \mathrm{~nm}$ IR laser and a $50 \times$ objective (yielding a calculated laser spot Airy diameter of 1.28 $\mu \mathrm{m})$. These maps were used to study the through core distribution of grafted chains and sulfonic acid groups in presulfonated and post-sulfonate (dry) samples of the most promising BVPE-crosslinked RG-CEM produced (ES-B10, see below). The sample stage was moved in the $x-y$ direction in 1.5 $\mu \mathrm{m}$ steps (slight under sampling). ${ }^{9}$

${ }^{13} \mathrm{C}$ solid-state NMR spectra $\left({ }^{1} \mathrm{H}\right.$ and ${ }^{19} \mathrm{~F}$ decoupled, crosspolarisation from ${ }^{1} \mathrm{H}, 12 \mathrm{kHz}$ MAS) were collected at the NMR Service at Durham University on a Bruker Avance III HD spectrometer $\left({ }^{1} \mathrm{H}\right.$ resonance at $\left.400 \mathrm{MHz}\right)$ using neat tetramethylsilane as the shift reference. To record spectra of the AEMs, the samples were dried in a relative humidity $\mathrm{RH}=0 \%$ desiccator to remove excess water. 

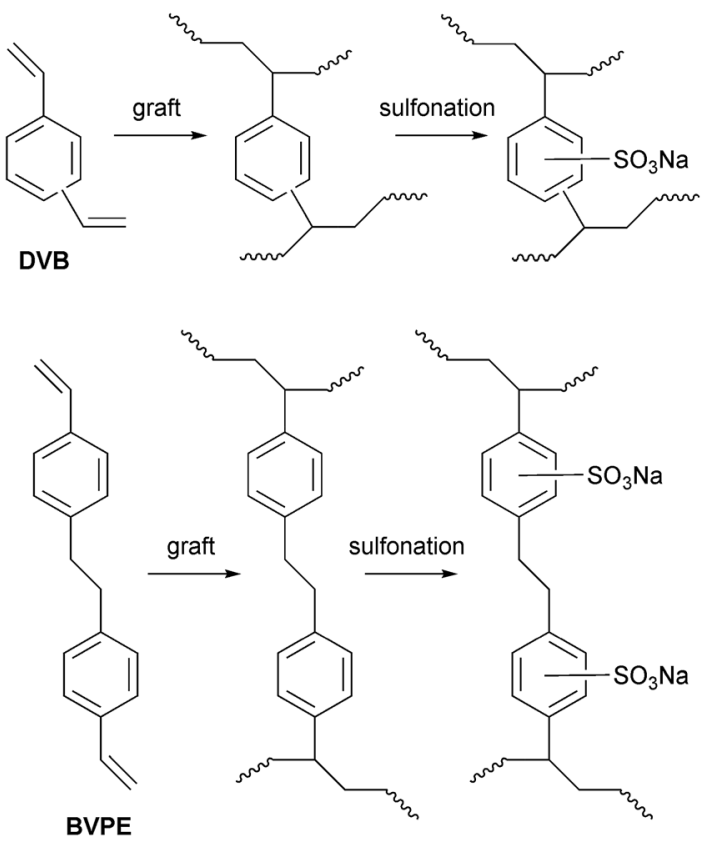

Scheme 2 An outline of the additional crosslinking introduced into the ETFE-styrene-based RG-CEMs (see Scheme 1) with the use of divinylbenzene (DVB) and bis(vinylphenyl)ethane (BVPE) in the radiation-grafting process. Note that the complete sulfonation of the crosslinking groups is shown but this is unlikely to occur in reality (the degree of sulfonation in this study is undetermined).

\section{Determination of the ion-exchange capacities (IEC)}

The IECs of the RG-CEMs (in the $\mathrm{H}^{+}$forms) were determined using an acid-base titration method. Samples of RG-CEM samples (ca. $25 \mathrm{~mm} \times 25 \mathrm{~mm}, \mathrm{H}^{+}$forms guaranteed by ion exchange using aqueous $\mathrm{HCl}\left(1.0 \mathrm{~mol} \mathrm{dm}^{-3}\right)$ followed by rigorous washing with UPW) were dried under vacuum at $50{ }^{\circ} \mathrm{C}$ overnight ( $c a .16 \mathrm{~h})$. The dry mass $\left(m_{\mathrm{d}}\right)$ of each RG-CEM sample was recorded before they were placed into separate polypropylene bottles containing aqueous $\mathrm{NaCl}$ solution $\left(25 \mathrm{~cm}^{3}\right.$, $1 \mathrm{~mol} \mathrm{dm}^{-3}$ ) and stirred overnight. The amounts of $\mathrm{H}^{+}$released into each solution were determined by titration of the solutions (which still contained the RG-CEM samples) with aqueous $\mathrm{KOH}$ $\left(0.1000 \pm 0.0001 \mathrm{~mol} \mathrm{dm}^{-3}\right)$ standardised titrant using an Metrohm 848 autotitrator fitted with a $\mathrm{pH}$ probe: the endpoints, $V_{\mathrm{EP}}$, were determined from the point of steepest gradient of the titration s-curve ( $\mathrm{pH} v$ s. volume of titrant added). The IEC for each sample was calculated using following equation (with the indicated units):

$$
\text { IEC }\left(\mathrm{mmol} \mathrm{g}^{-1}\right)=\frac{\left.V_{\mathrm{EP}}\left(\mathrm{cm}^{3}\right) \times 0.1000(\mathrm{mmol} \mathrm{cm})^{-3}\right)}{m_{\mathrm{d}}(\mathrm{g})}
$$

\section{Gravimetric water uptakes (WU) and fixed charge density $\left(C_{\text {fix }}\right)$}

Gravimetric water uptake (WU) is a measurement of an IEM's ability to absorb water. Fully hydrated samples of RG-CEMs (after boiling the $\mathrm{Na}^{+}$forms in deionised water) were blotted dry with filter paper (to remove any surface water) and weighed $\left(m_{\mathrm{h}}\right)$. The samples of membrane were then dried in a vacuum oven overnight ( $\mathrm{ca} .16 \mathrm{~h}$ ) at $50{ }^{\circ} \mathrm{C}$ before being weighed again $\left(m_{\mathrm{d}}\right)$ immediately after removal from the oven. The WU value for each RG-CEM sample was calculated as follows:

$$
\mathrm{WU}(\%)=100 \times \frac{m_{\mathrm{h}}-m_{\mathrm{d}}}{m_{\mathrm{d}}}
$$

The fixed charge densities $\left(C_{\mathrm{fix}}\right)$ is a measure of the amount of charge per unit mass of $\mathrm{H}_{2} \mathrm{O}$ molecules in an IEM. ${ }^{10}$ The $C_{\mathrm{fix}}$ values were calculated from the WU and IEC data as follows:

$$
C_{\text {fix }}\left(\operatorname{mmol~g}_{\mathrm{H}_{2} \mathrm{O}}{ }^{-1}\right)=\frac{\operatorname{IEC}\left(\mathrm{mmol} \mathrm{g}^{-1}\right) \times m_{\mathrm{d}}(\mathrm{g})}{m_{\mathrm{h}}(\mathrm{g})-m_{\mathrm{d}}(\mathrm{g})}
$$

where $m_{\mathrm{h}}-m_{\mathrm{d}}$ gives the mass of $\mathrm{H}_{2} \mathrm{O}$ molecules in each fully hydrated RG-CEM sample tested.

\section{Through-plane conductivities $\left(\sigma_{\mathrm{Na}^{+}}\right)$of the $\mathrm{Na}^{+}$form RG-CEMs at room temperature and area specific resistance (ASR)}

The through-plane resistance of each RG-CEM was determined by using electrochemical impedance spectroscopy with the 2probe method we previously reported. ${ }^{11}$ For the purpose of this membrane development study, we used this method, which measures the intrinsic through-plane conductivities of the $\mathrm{Na}^{+}$ form RG-CEMs in water without the presence of excess co-ions or counter-ions: i.e. the only mobile ions present (not covalently attached to the polymer) were the $\mathrm{Na}^{+}$ions that were chargebalancing the negative sulfonate groups (attached to the polymer). Obviously, these conductivities will differ to those measured with the RG-CEMs submerged in aqueous salt (e.g. $\mathrm{NaCl}$ ) solutions, which are a function of the solutions as well as the membrane. These will be determined in a future study that tests the RG-CEMs in actual RED cells (alongside anionexchange membranes).

Samples of each RG-CEM (in $\mathrm{Na}^{+}$forms, diameter $\varnothing=2.2$ $\mathrm{cm})$ were hot-pressed between two carbon cloth electrodes $(\varnothing=$ $1.3 \mathrm{~cm}, A=1.33 \mathrm{~cm}^{2}$ CeTech) with $150 \pm 50 \mathrm{~kg} \mathrm{~cm}{ }^{-2}$ force at $80{ }^{\circ} \mathrm{C}$ : the carbon-cloth electrodes were pressed so that the PTFE-bonded Vulcan-coated faces were hot-pressed against the RG-CEM sample (with the uncoated sides facing away from the RG-CEM sample). Each mini membrane electrode assemblies (mMEA) was fixed between two graphite electrodes and submerged in UPW at room temperature for at least $16 \mathrm{~h}$ to rehydrate. An electrochemical impedance spectrum of each mMEA was recorded using a Solartron 1260 frequency response analyser/Solartron 1287 electrochemical interface (controlled by ZPlot software, Scribner Associates) with the assembly still submerged in UPW at room temperature: an a.c. voltage amplitude of $50 \mathrm{mV}$ was used over a frequency range $1 \mathrm{~Hz}$ to 1 MHz. The resistances of each mMEA $\left(R_{\text {EIS }} / \Omega\right)$ was taken as the high-frequency $x$-intercept of the resulting Nyquist plot. The resistance of each RG-CEM sample $\left(R_{\mathrm{M}} / \Omega\right)$ was obtained by correction of the $R_{\text {EIS }}$ value by subtraction of the resistance of the circuit and electrodes in the absence of a RG-CEM sample $\left(R_{0} / \Omega\right)$.

The through-plane conductivity $\left(\sigma_{\mathrm{Na}^{+}}\right)$of each RG-CEM sample was calculated as follows: 


$$
\left.\sigma_{\mathrm{Na}^{+}}(\mathrm{S} \mathrm{cm})^{-1}\right)=\frac{t_{\mathrm{h}}(\mathrm{cm})}{\operatorname{ASR}\left(\Omega \mathrm{cm}^{2}\right)}=\frac{t_{\mathrm{h}}(\mathrm{cm})}{R_{\mathrm{M}}(\Omega) \times A\left(\mathrm{~cm}^{2}\right)}
$$

where $R_{\mathrm{M}}=R_{\mathrm{EIS}}-R_{0}, t_{\mathrm{h}}$ is the thickness of the fully hydrated RG-CEM sample ( $\mathrm{Na}^{+}$form) and ASR is the area specific resistance $(=R \times A)$.

\section{Determination of permselectivities $(\alpha)$}

Permselectivity was determined using the static membrane potential method ${ }^{\mathbf{1 2}}$ with an effective membrane area of $50 \mathrm{~mm}$ $\times 50 \mathrm{~mm}$. Prior to measurement, each RG-CEM was equilibrated in aqueous $\mathrm{NaCl}$ solution $\left(1 \mathrm{~mol} \mathrm{dm}^{-3}\right)$ for $24 \mathrm{~h}$. The experimental cell consists of two compartments separated by the membrane under investigation. One compartment is filled

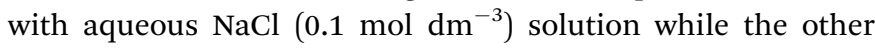
contains a more concentrated aqueous $\mathrm{NaCl}\left(0.5 \mathrm{~mol} \mathrm{dm}^{-3}\right)$ solution. Both solutions were kept mobile by magnetic stirring (600 rpm) while fresh solution was circulated into the cell at a rate of $5 \mathrm{~cm}^{3} \mathrm{~min}^{-1}$ using a peristaltic pump. After $40 \mathrm{~min}$, and when the system has reached a steady state potential, the potential difference between the two compartments was measured using $\mathrm{Ag} / \mathrm{AgCl}$ reference electrodes (RE-5B, BASi). Three replicate measurements were performed for each RGCEM, and the membrane permselectivity is calculated from the mean as:

$$
\alpha(\%)=100 \times \frac{E_{\mathrm{M}}-E_{0}}{E_{\mathrm{T}}}
$$

where $E_{\mathrm{M}}$ was the measured membrane potential, $E_{0}$ was the offset potential measured as the potential difference between the two REs immersed in aqueous $\mathrm{NaCl}\left(0.5 \mathrm{~mol} \mathrm{dm}^{-3}\right)$ solution, and $E_{\mathrm{T}}$ is theoretical potential (varied slightly on different days due to the cell temperature changing) calculated using: ${ }^{13}$

$$
E_{\mathrm{T}}=\frac{R T}{n F} \ln \left(\frac{a_{\mathrm{d}}}{a_{\mathrm{c}}}\right)
$$

where $R$ is the gas constant, $T$ is the thermodynamic temperature (K), $F$ is Faraday's constant, $n=1$ (number of $\mathrm{e}^{-}$transferred in the cell reactions), $a_{\mathrm{d}}$ is the activity of the dilute solution, and $a_{\mathrm{c}}$ is the activity of the concentrated solution.

\section{Results and discussion}

Radiation-grafted cation-exchange membranes (RG-CEM) fabricated without the use of a divinyl-type crosslinking agent

A series of PVDF-based RG-CEMs were fabricated using two types of grafting monomers (Scheme 1): styrene (requiring subsequent sulfonation to form RG-CEMs) or 4-vinylbenzene sodium sulfonate (VBS, does not require additional sulfonation). A series of ETFE-based RG-CEMs were also produced using styrene. For all three variants (Scheme 1), numerous experiments were conducted to study the effect of varying the synthesis parameters (data not shown: see the PhD thesis by $\mathrm{Dr}$ Willson for more details); ${ }^{13}$ the aim of these experiments was to fabricate an RG-CEM of each type with comparable ionexchange capacities (an IEC of $c a .2 .5 \mathrm{mmol} \mathrm{g}^{-1}$ was the target at this stage). The conditions used to obtain the final down- selected RG-CEMs (designated PS-0, PV-0, and ES-0) are summarised in Table 1. The Raman and solid-state NMR spectra of these RG-CEMs are presented in Fig. S2-S7 in the ESI.t

As can be seen from Table 1, IECs in the range 2.31$2.60 \mathrm{mmol} \mathrm{g}^{-1}$ were achieved across the three RG-CEM types. The use of styrene monomer resulted in thicker hydrated RGCEMs ( $c f$. with the use of VBS grafting agent) but this is, at least partially, due to the slightly higher IECs (note: due to the different grafting conditions used, for each monomer/substrate combination, to try and get as similar IECs as possible, this study does not allow a full parametric comparison). All three RG-CEMs exhibited the same gravimetric water uptakes (WU) and through-plane $\mathrm{Na}^{+}$conductivities $\left(\sigma_{\mathrm{Na}^{+}}\right.$, in water at room temperature). Disappointingly, all three RG-CEMS exhibited low permselectivities, particularly PV-0 ( $\alpha$ values well below the study's target of $90 \%$ or higher). As high $\alpha$ is important for high performance in RED cells, ${ }^{3}$ the decision was made to introduce crosslinking (Scheme 2) into the RG-CEMs to investigate whether this enhances $\alpha$ values. ${ }^{14}$ Owing to the availability of a large quantity of ETFE precursor films and the poorer attributes of RG-CEMs made with VBS monomer, the following crosslinking studies focused on the styrene-sulfonation method using ETFE.

\section{RG-CEMs made using divinylbenzene (DVB) crosslinker in the grafting mixture}

The first crosslinking agent tested was the commercially available divinylbenzene (DVB, Scheme 2). The synthesis conditions and key properties of the RG-CEMs synthesised with the use of 0,5 , and $10 \%$ mol DVB in the grafting step are summarised in Table 2: these were designated ES-D0, ES-D5, and ES-D10, respectively. The Raman and solid-state NMR characterisation data are presented in Fig. S8-S11 in the ESI.t

As can be seen in these data, the use of 5\% mol DVB crosslinker yields an RG-CEM with a higher IEC but lower $\alpha$ and $\sigma_{\mathrm{Na}^{+}}$ values (compared to the uncrosslinked ES-D0 benchmark made using the same synthesis conditions without use of DVB). $\S$ Increasing the DVB content in the grafting mixture to $10 \% \mathrm{~mol}$ improved the $\alpha$ of the resulting RG-CEM but further lowered $\sigma_{\mathrm{Na}^{+}}$. As $\sigma_{\mathrm{Na}^{+}}<10 \mathrm{mS} \mathrm{cm}{ }^{-1}$ at room temperature are too low, it was decided to study the use of a different crosslinking comonomer.

\section{RG-CEMs made using bis(vinylphenyl)ethane (BVPE) crosslinker in the grafting mixture}

The use of an alternative crosslinker (BVPE, Scheme 2) was investigated to introduce more flexible crosslinks (more spatially separated vinyl groups). BVPE has been used before for the synthesis of RG-CEMs. ${ }^{\mathbf{8 , 1 5}}$ These prior studies have involved the irradiation of the base films in inert atmospheres. However in this study, following on from our fuel cell anion-exchange

$\S$ Note that ES-D0 has a lower IEC than ES-0 (previous section). This is because a shorter graft time was adopted to also help increase $\alpha$ values by lowering IEC and water uptakes $(\alpha=80 \%$ for the $8 \mathrm{~h}$ graft time compared to $65 \%$ for the $72 \mathrm{~h}$ graft time). 
membrane work ${ }^{10}$ we use a high power electron-beam irradiation source ( $5 \mathrm{MeV}$ ), which leads to extremely fast dose rates (10 kGy absorbed dose in the few seconds the films take to pass under the beam), and we irradiated the base films in air (the peroxidation method). This production method is much more amenable to scale-up (we are currently discussing this with several commercial entities). The use of high radiation dose rates also leads to a higher concentration of (short) grafted chains ( $c f$. a low concentration of long grafted chains obtained with the use of low radiation dose rates), which results in superior in situ RG-CEM performances (e.g. resistances and durabilities in fuel cells). ${ }^{16}$

The synthesis and characterisation of BVPE is detailed in the ESI: (the Raman spectrum is presented in Fig. 1). The synthesis conditions and key properties of the RG-CEMs synthesised with the use of 0,5 , and $10 \%$ mol BVPE in the grafting step are summarised in Table 3: these were designated ES-B0, ES-B5, and ES-B10, respectively.

Spectroscopic characterisation. Raman and solid-state NMR spectral characterisation data of the pre- and post-sulfonated membranes are presented in Fig. 2 and 3. The pre-sulfonated membranes, ETFE- $g$-polystyrene and ETFE- $g$-poly(styrene-coBVPE), were firstly analysed by Raman spectroscopy (Fig. 2, top). Polystyrene graft units exhibit a very strong, characteristic Raman peak at $1001 \mathrm{~cm}^{-1}$, which is not present in the spectra of BVPE or the polymers made from BVPE (containing only paradisubstituted benzene rings). It is clear that addition of BVPE into the grafting mixture has boosted the grafting of styrene, as has been previously reported; ${ }^{8,14}$ this partially explains the enhanced IEC of ES-B5, and ES-B10 compared to ES-B0. BVPE monomer gives a very characteristic Raman peak at $1630 \mathrm{~cm}^{-1}$, which is due to the $\mathrm{C}=\mathrm{C}$ stretch of vinyl groups attached to benzene rings (reported for styrene monomer). ${ }^{17}$ Low intensities of this peak can be seen in the spectrum of ETFE-g-poly(styrene$c o$-BVPE) prepared using $10 \%$ mol BVPE (slightly less so when $5 \%$ mol was used), which indicates that poly(BVPE) inclusion has occurred, potentially with $<100 \%$ consumption of the vinyl groups. Similarly, there is also a strong, characteristic peak at $1183 \mathrm{~cm}^{-1}$ in the Raman spectrum of BVPE monomer. The peak at 1183 in the spectra of the ETFE- $g$-poly(styrene-co-BVPE)

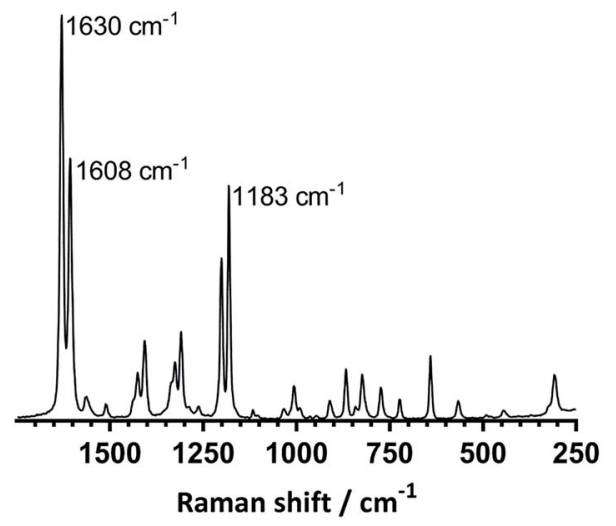

Fig. 1 The Raman spectrum of the synthesised BVPE $(\lambda=532 \mathrm{~nm})$. membranes is enhanced in intensity, in relation to the neighbouring peak at $1202 \mathrm{~cm}^{-1}$, when compared to the spectrum of ETFE- $g$-(polystyrene); this provides further evidence of poly(BVPE) inclusion in the pre-sulfonated precursors to ES-B5 and ES-B10. The Raman maps (Fig. S12 in the ESI:) show that grafting has occurred throughout the core of ES-B10 with minor inhomogeneity.

The ${ }^{13} \mathrm{C}$ solid-state NMR spectra (Fig. 2, bottom) of the presulfonated ETFE-g-poly(styrene-co-BVPE) membranes show more intense aromatic $(\delta=146$ and $128 \mathrm{ppm})$ and polystyrenederived $-\mathrm{CH}_{2}-\mathrm{CH}(\mathrm{Ph})-(\delta=41 \mathrm{ppm}$, with shoulder at $\delta=45$ $\mathrm{ppm})$ peaks, compared to the spectrum of the poly(BVPE)-free ETFE- $g$-poly(styrene- $c o$-BVPE) membrane (when intensities are normalised to the ETFE-derived $-\mathrm{CH}_{2}-$ carbon peak at $\delta=21$ $\mathrm{ppm})$. This enhanced content of benzene-ring-containing grafted chains again explains the higher IECs of ES-B5 and ES-B10 compared to ES-BO. However, ${ }^{13} \mathrm{C}$ NMR is not useful for specifically confirming the presence of poly(BVPE) content. The peaks at $\delta=119,112$, and $30 \mathrm{ppm}$ derive from the ETFE base film.

The Raman spectra of the final, sulfonated ES-B0, ES-B5, and ES-B10 RG-CEMs are presented in Fig. 3 (top). These spectra are dramatically different to the spectra of the pre-sulfonated analogues (Fig. 2, top). Sulfonation is confirmed by the appearance of the peaks at 1197, 1132, 1043, and $636 \mathrm{~cm}^{-1},^{18}$ along with the disappearance of the peak at $1000 \mathrm{~cm}^{-1}$ observed with the polystyrene component of the pre-sulfonated analogues; the weak peak at $1629 \mathrm{~cm}^{-1}$ (due to pre-sulfonated BVPE-derived components) is also no longer visible in the spectra of the sulfonated RG-CEMs. The peak at $1132 \mathrm{~cm}^{-1}$ shows that sulfonation levels are higher with increasing poly(BVPE) contents, as expected from the observed increases in IEC. The disappearance of the $1000 \mathrm{~cm}^{-1}$ peak suggests a high degree of sulfonation of the benzene rings of the polystyrene grafts, however it is not possible to estimate the degree of sulfonation of the benzene-rings of the BVPE crosslinks (due to the appearance of a broad peak at $1197 \mathrm{~cm}^{-1}$, interfering with the analysis of the intensity of the BVPE-related peak at $1183 \mathrm{~cm}^{-1}$ ). The Raman maps (Fig. S12 in the ESI:) show that sulfonation has occurred throughout the core of ES-B10 with minor inhomogeneities.

The ${ }^{13} \mathrm{C}$ solid-state NMR spectra of ES-B0, ES-B5, and ESB10 are presented in Fig. 3 (bottom). Sulfonation primarily changes the shape of aromatic peak at $\delta=148$ and $127 \mathrm{ppm}$ and leads to a new peak at $\delta=141 \mathrm{ppm}$ (as previously reported for aromatic carbons bonded to $-\mathrm{SO}_{3}{ }^{-}$groups). ${ }^{19}$ All of the aforementioned spectra again confirm higher grafting levels (i.e. enhanced aromatic contents) for ES-B5 and ES-B10 compared to ES-BO. However, due to the broad overlapping peaks obtained with insoluble RG-CEMs (that can't be studied using more high-resolution NMR techniques), again no information on the degree of sulfonation can be elucidated.

Physical properties. Unlike with the use of DVB, the use of $5 \%$ mol BVPE in the grafting mixture led to an RG-CEM with significantly increased IEC and $\sigma_{\mathrm{Na}^{+}}$. However, $\alpha$ was only slightly improved and still below $90 \%$, while the water content 


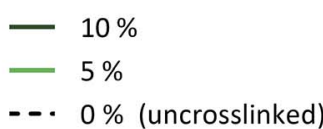

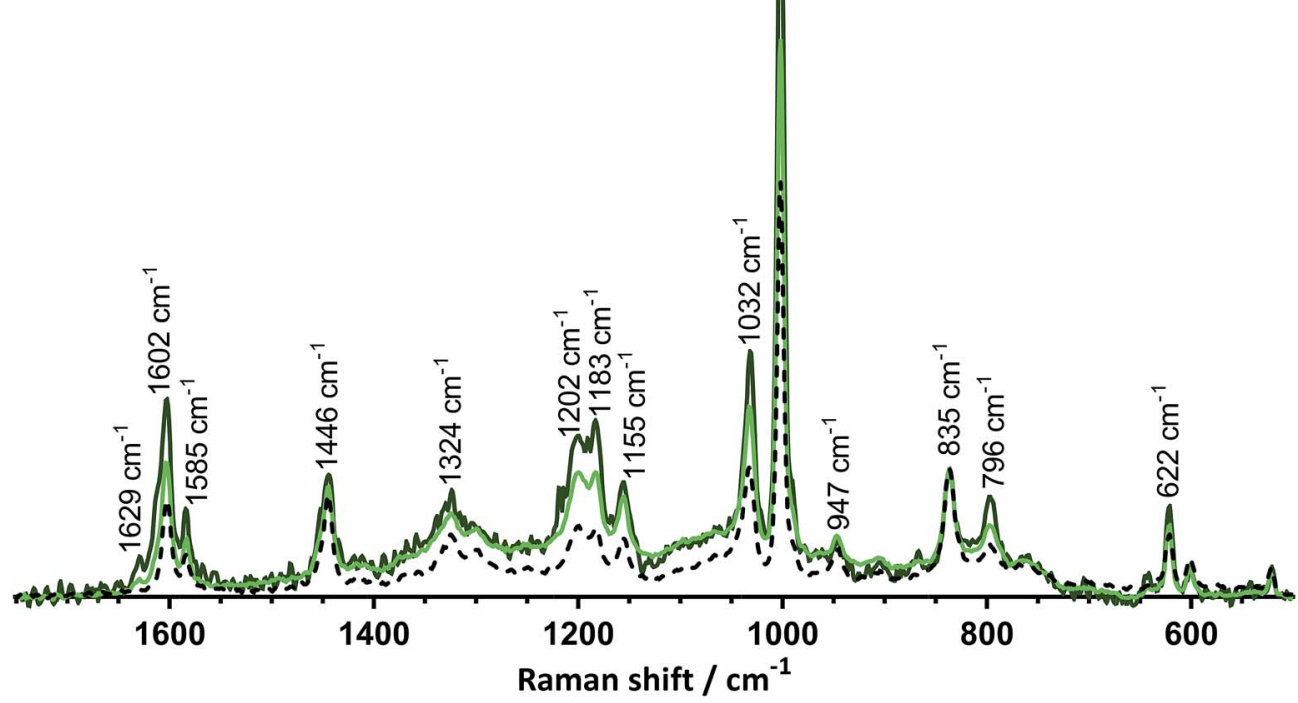

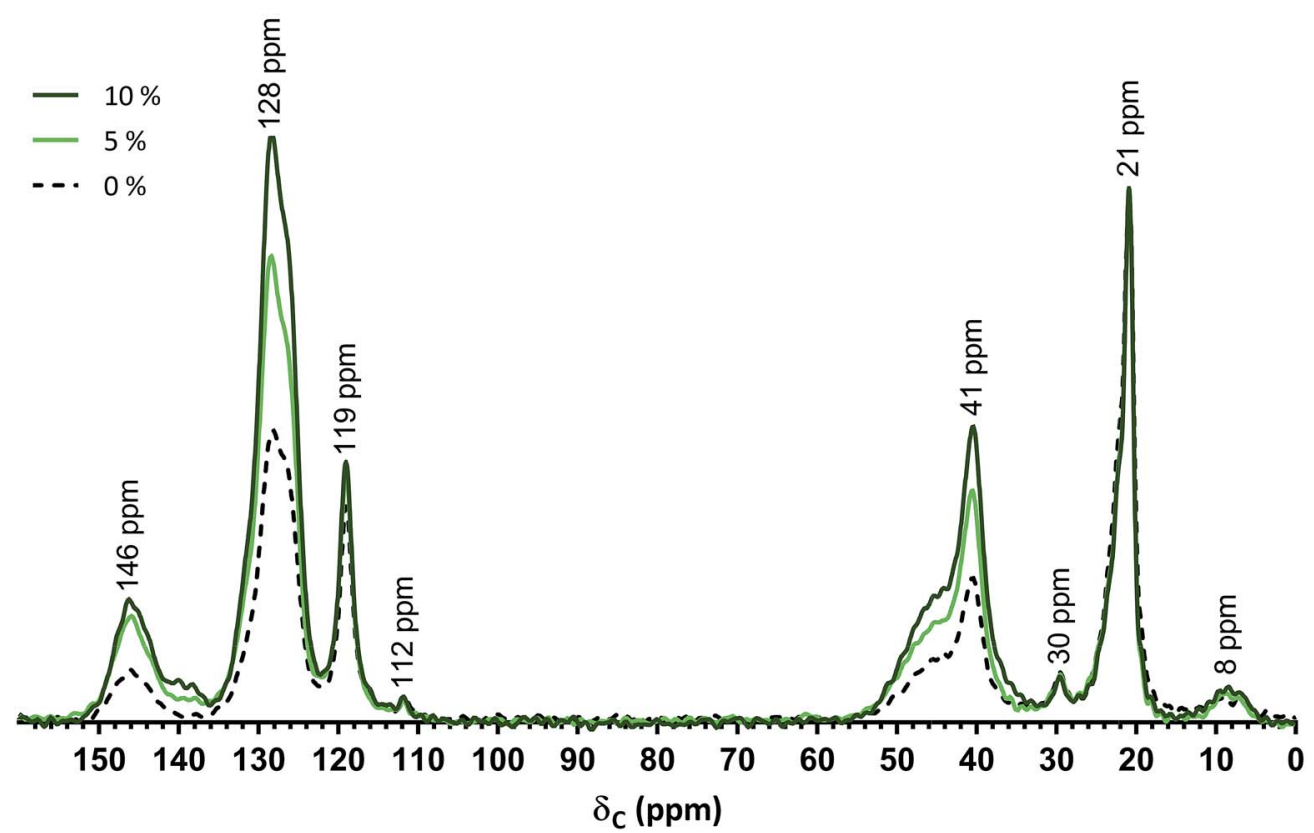

Fig. 2 The Raman spectra (top, $\lambda=532 \mathrm{~nm}$, normalised to the ETFE peak at $835 \mathrm{~cm}^{-1}$ ) and ${ }^{13} \mathrm{C}$ solid-state NMR spectra (bottom, TMS shift reference, normalised to the ETFE peak at $21 \mathrm{ppm}$ ) of the pre-sulfonated ETFE-g-poly(styrene-Co-BVPE) membranes used to form ES-B0, ES-B5, and ES-B10. The positions of the most distinct peaks are displayed.

of the RG-CEM had also increased. This suggests that with the use of $5 \%$ mol BVPE, the effects of the enhanced IEC are not adequately offset by the addition of crosslinking. The use of $10 \%$ mol BVPE in the grafting mixture, however, led to an RGCEM (ES-B10) that exhibited a similar thickness, WU and $\sigma_{\mathrm{Na}^{+}}$ to the uncrosslinked benchmark (ES-BO) but now with an above target $\alpha$ of $92 \%$. ES-B10 now has the baseline properties to warrant more detailed evaluation.
Fig. 4 provides a summary of the properties of the three BVPE-based RG-CEMs discussed in this study. It is clear that the enhanced IECs, with the use of BVPE in the grafting mixture, have led to enhanced fixed charge densities, which may explain the enhanced $\alpha$ values. Importantly, the presence of crosslinks also means the water uptakes and hydrated thicknesses of the RG-CEMs have not increased excessively with the higher IECs. 

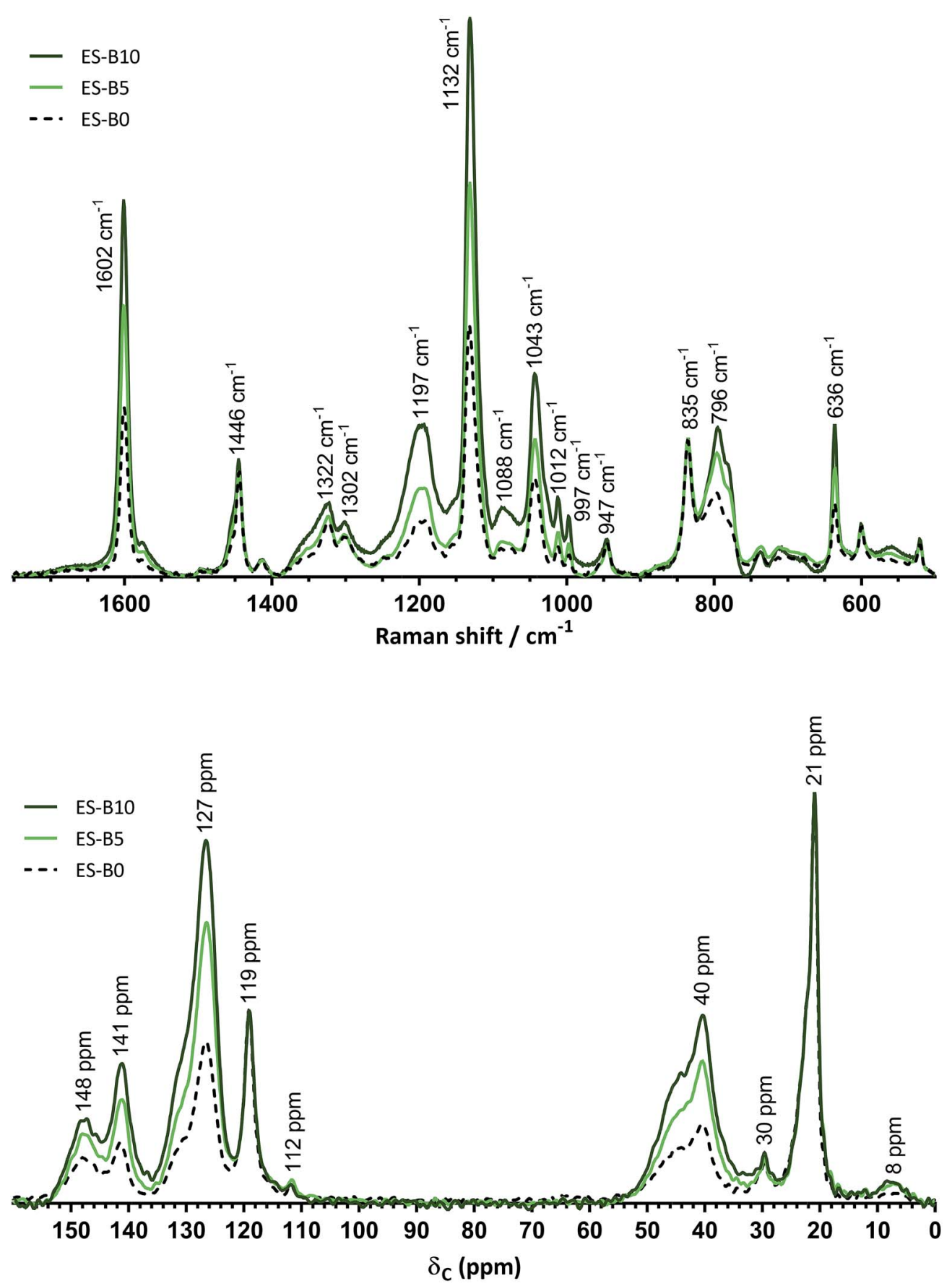

Fig. 3 The Raman spectra (top, $\lambda=785 \mathrm{~nm}$, normalised to the ETFE peak at $835 \mathrm{~cm}^{-1}$ ) and ${ }^{13} \mathrm{C}$ solid-state NMR spectra (bottom, TMS shift reference, normalised to the ETFE peak at 21 ppm) of ES-B0, ES-B5, and ES-B10. The positions of the most distinct peaks are displayed.

An initial property correlation study for all of the RG-CEMs synthesised for this study

Fig. S13-S15 in the ESIt present plots of three key properties $\left(\sigma_{\mathrm{Na}^{+}}, \mathrm{ASR}\right.$, and permselectivity), as a function of the other properties measured (including IEC, WU, and $C_{\text {fix }}$ ), for each RGCEM mentioned in Tables 1-3. These plots omit error bars for visual clarity. It is clear from these data that none of these key properties correlate with IEC; this is not unexpected due to the different fundamental nature of each of these RG-CEMs. The strongest correlations are between $\sigma_{\mathrm{Na}^{+}}$and ASR $v s$. WU, where RG-CEMs with higher WU values exhibit higher $\sigma_{\mathrm{Na}^{+}}$, and hence lower ASR, values (Fig. 5 top and middle). There are weaker correlations between $\sigma_{\mathrm{Na}^{+}}$and ASR $v s$. $C_{\text {fix }}$, where RG-CEMs with higher $C_{\text {fix }}$ values lead to lower $\sigma_{\mathrm{Na}^{+}}$(higher ASR) values.

Permselectivities correlate less well with all the other properties. However, the data showing the variation of $\alpha$ values as a function of $C_{\text {fix }}$ hint at each RG-CEM series (uncrosslinked, dense DVB-, and less-dense BVPE-crosslinked) having independent correlations with $C_{\text {fix }}$ (Fig. 5 bottom). In general terms, 

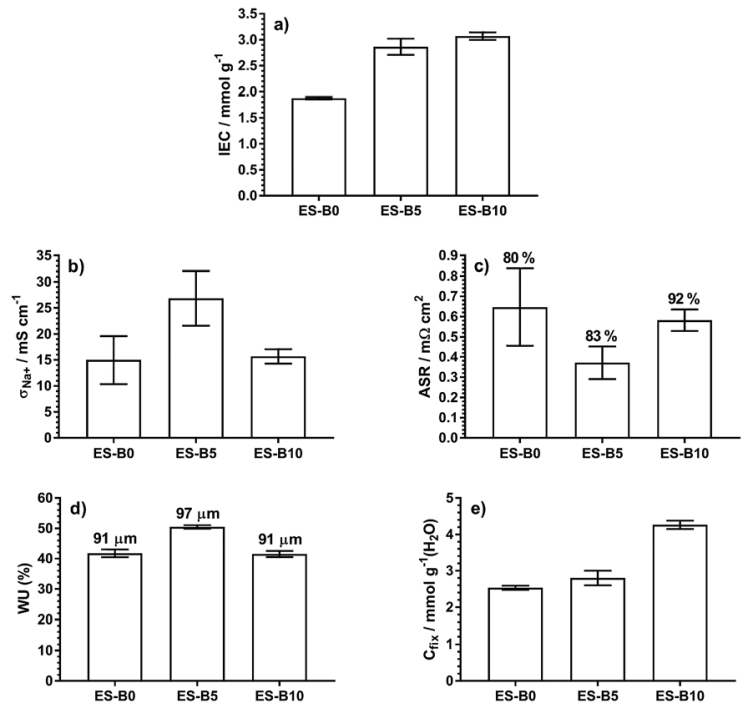

Fig. 4 A summary of the various experimentally measured properties for ES-B0, ES-B5, and ES-B10: (a) ion-exchange capacity (titration on $\mathrm{H}^{+}$form RG-CEMs, units in mmol cationic groups charges per $\mathrm{g}$ of dehydrated $\mathrm{H}^{+}$form $\mathrm{RG}-\mathrm{CEM}$ ); (b) conductivities of the $\mathrm{Na}^{+}$-form RGCEMs in water at room temperature (through-plane, 2-probe impedance spectroscopy data); (c) areas specific resistances of the $\mathrm{Na}^{+}$-form RG-CEMs (the percentages shown give the associated permselectivities, $\alpha$ ); (d) gravimetric water uptakes (with the associated hydrated thicknesses given above the bars); (e) fixed charged density $\left(C_{\text {fix }}\right)$. Error bars are the sample standard deviations from measurements on $n=3$ samples of each RG-CEM ( $n=4$ for the WU data).

IEMs with higher $C_{\mathrm{fix}}$ are expected to possess stronger co-ion exclusion, and is a potential indicator of high permselectivity. ${ }^{20}$ Obviously, more studies, involving a larger number of RG-CEMs of each series, are required before firm conclusions can be made. However, these data further support the use of BVPE crosslinker in the grafting mixtures, as this produces RGCEMs that can achieve higher $\alpha$ values (compared to the uncrosslinked variants) without leading to detrimentally low conductivities.

\section{Further discussion and context}

The permselectivity of ES-B10 of $92 \%$ is approaching the values exhibited by commercial CEMs. For example, Table 1 in ref. 21 presents the experimentally determined permselectivities of a range of CEMs (Fumatech Fumasep ${ }^{\circledR}$ FKE [thickness 50-70 $\mu \mathrm{m}$, IEC $=1.36$ meq. $\mathrm{g}^{-1}$ ] and FKD [thickness 90-100 $\mu \mathrm{m}$, IEC $=1.146$ meq. $\left.\mathrm{g}^{-1}\right]$, Tokuyama Neosepta ${ }^{\circledR}$ CM-1 [thickness 120-170 $\mu \mathrm{m}$, IEC $=2.30 \mathrm{meq} \cdot \mathrm{g}^{-1}$ ] and CMX [thickness 140-200 $\mu \mathrm{m}$, IEC $=1.62 \mathrm{meq} \cdot \mathrm{g}^{-1}$ ] and AGC Selemion ${ }^{\circledR}$ CMV [thickness $130 \mu \mathrm{m}$, IEC $=2.01 \mathrm{meq} \cdot \mathrm{g}^{-1}$ ]), which range from $90-99 \%$ ( $c f$. $92-98 \%$ reported by the suppliers). These values are backed up data presented in a more recent review of ion-exchange membranes for RED (Table 2 in ref. 22). More recently, various types of Fujifilm CEMs (115-155 $\mu \mathrm{m}$ thick, IEC around 1.1 meq. $\left.\mathrm{g}^{-1}\right)$ are being considered as front runners for use in RED cells and these can have permselectivities ranging from $90-95 \% .{ }^{23}$ All of these
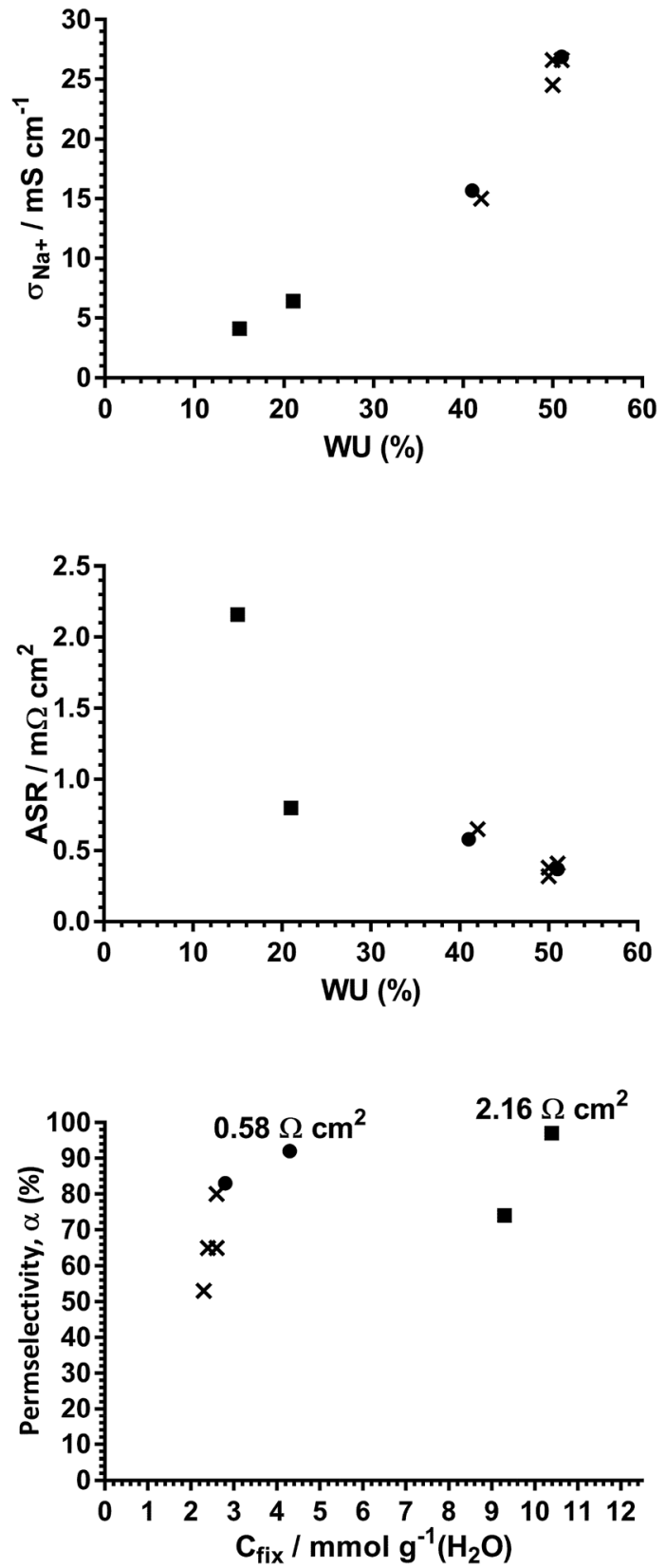

Fig. 5 Select property correlations of the RG-CEMs reported in Tables $1-3$ in the main article (other correlations are given in Fig. S13-S15 in the ESI $: x=$ uncrosslinked variants, $\mathbf{\square}=$ DVB-crosslinked variants, and $\mathbf{0}=$ BVPE-crosslinked variants. The ASR values of the two RGCEMs with $\alpha>90 \%$ are also given. The values presented are the means with error bars omitted for visual clarity.

CEMs have ASRs ranging between 1 and $3 \Omega \mathrm{cm}^{2}$ when measured in aqueous $0.5 \mathrm{M} \mathrm{NaCl}$ at $25{ }^{\circ} \mathrm{C}$. Despite the ASR values being measured using a different method, this data suggests that correctly cross-linked RG-CEMs have a promising balance of low resistance and high enough permselectivities.

The cost of radiation-grafted IEMs are generally perceived to be too high compared to commercial types, especially as the use of radiation grafted IEMs for electrodialysis (ED) has been 
debated over many years. However, it is also felt that commercial ED membranes are not always suitable for RED and thinner membranes of lower area resistance (with no compromise in permselectivity) are essential to increase the power outputs. The question of the commercial viability of radiation-grafted IEMs is now being directly challenged (especially with the use of $\mathrm{MeV}$ electron-beam irradiation yielding extremely fast dose rates). For example, Gaia Membranes (a 2019 spin-out from the Paul Scherrer Institute in Switzerland) is commercialising a radiation-grafted amphoteric membrane (Amphion ${ }^{\mathrm{TM}}$ ) for use in vanadium redox flow batteries. ${ }^{24}$

\section{Conclusions}

Reverse electrodialysis cells (RED - a salinity gradient power technology) require both cation- and anion-exchange membranes with both high conductivities and high permselectivities. This initial, ex situ study on the development of REDapplicable radiation-grafted cation-exchange membranes (RGCEM) focused on these two key properties.

A range of RG-CEMs were synthesised, both with and without crosslinking (via the use of divinyl-based crosslinking agents). The uncrosslinked RG-CEMs exhibited low permselectivities, especially with the use of a one-step synthesis method involving 4-vinylbenzene sodium sulfonate grafting monomer ( $c f$. RGCEMs synthesised using a two-step method involving the grafting of styrene monomer with a subsequent sulfonation step). The RG-CEMs synthesised with (inflexible) divinylbenzene crosslinks exhibited higher permselectivities but with undesirable decreases in $\mathrm{Na}^{+}$cation conductivity. The introduction of more flexible crosslinks, with the use of bis(vinylphenyl)ethane (BVPE) crosslinking monomer, yielded a higher permselectivity of $92 \%$ without lowering $\mathrm{Na}^{+}$ion conductivity ( $c f$. the uncrosslinked benchmark).

This study concludes that RG-CEMs containing BVPE-based covalent crosslinks have high enough permselectivities to warrant a much more detailed study. Future studies will involve more application-related performances including resistance determinations when in contact with aqueous salt solutions, monovalent ion selectivity and fouling resistance measurements, and cost reduction strategies (i.e. replacing the partially fluorinated precursor films with non-fluorinated variants such as polyethylene films). Radiation-grafted anion-exchange membranes, with and without crosslinking, should also be evaluated alongside the RG-CEMs in RED cell test set-ups.

\section{Conflicts of interest}

There are no conflicts to declare.

\section{Acknowledgements}

This research was funded by the UK's Engineering and Physical Sciences Research Council (EPSRC grants EP/I004882/1, EP/ M022749/1, and EP/R044163/1). Additional funds for Dr Willson were provided by the University of Surrey's Doctoral Training Grant (EPSRC).

\section{References}

1 (a) Y. Ming and C. Y. Tang, Desalination, 2018, 425, 156; (b) R. A. Tufa, S. Pawlowski, J. Veerman, K. Bouzek, E. Fontananova, G. di Profio, S. Velizarov, J. G. Crespo, K. Nijmeijer and E. Curcio, Appl. Energy, 2018, 225, 290; (c) B. E. Logan and M. Elimelech, Nature, 2012, 488, 313; (d) G. Z. Ramon, B. J. Feinberg and E. M. V. Hoek, Energy Environ. Sci., 2011, 4, 4423.

2 (a) J. G. Hong, B. Zhang, S. Glabman, N. Uzal, X. Dou, H. Zhang, X. Wei and Y. Chen, J. Membr. Sci., 2015, 486, 71; (b) J. R. Varcoe, P. Atanassov, D. R. Dekel, A. M. Herring, M. A. Hickner, P. A. Kohl, A. R. Kucernak, W. E. Mustain, K. Nijmeijer, K. Scott, T. Xu and L. Zhuang, Energy Environ. Sci., 2014, 7, 3135.

3 (a) A. Zlotorowicz, R. V. Strand, O. S. Burheim, Ø. Wilhelmsen and S. Kjelstrup, J. Membr. Sci., 2017, 523, 402; (b) E. Güler, R. Elizen, D. A. Vermaas, M. Saakes and K. Nijmeijer, J. Membr. Sci., 2013, 446, 266; (c) G. M. Geise, M. A. Hickner and B. E. Logan, ACS Appl. Mater. Interfaces, 2013, 5, 10294.

4 (a) X. Tong, B. Zhang and Y. Chen, J. Membr. Sci., 2016, 516, 162; (b) J. Moreno, V. Díez, M. Saakes and K. Nijmeijer, J. Membr. Sci., 2018, 550, 155; (c) E. Güler, W. van Baak, M. Saakes and K. Nijmeijer, J. Membr. Sci., 2014, 455, 254.

5 (a) L. Wang, M. Bellini, H. A. Miller and J. R. Varcoe, J. Mater. Chem. A, 2018, 6, 15404; (b) M. M. Nasef, S. A. Gürsel, D. Karabelli and O. Güven, Prog. Polym. Sci., 2016, 63, 1; (c) O. Nibel, T. J. Schmidt and L. Gubler, J. Electrochem. Soc., 2016, 163, A2563; (d) L. Gubler, S. A. Gursel and G. G. Scherer, Fuel Cells, 2005, 5, 317.

6 J. A. Horsfall and K. V. Lovell, Eur. Polym. J., 2002, 38, 1671.

7 M. M. Nasef, H. Saidi and K. Z. M. Dahlan, J. Membr. Sci., 2009, 339, 115.

8 S. Holmberg, J. H. Näsman and F. Sundholm, Polym. Adv. Technol., 1996, 9, 121.

9 W. H. Lee, C. Crean, J. R. Varcoe and R. Bance-Soualhi, RSC Adv., 2017, 7, 47726.

10 J. Choi, S. C. Yang, N.-J. Jeong, H. Kim and W.-S. Kim, Langmuir, 2018, 34, 10837.

11 J. Ponce-Gonzalez, D. K. Whelligan, L. Wang, R. BanceSoualhi, Y. Wang, Y. Peng, H. Peng, D. C. Apperley, H. N. Sarode, T. P. Pandey, A. G. Divekar, S. Seifert, A. M. Herring, L. Zhuang and J. R. Varcoe, Energy Environ. Sci., 2016, 9, 3724-3735.

12 G. M. Geise, H. J. Cassady, D. R. Paul, B. E. Logan and M. A. Hickner, Phys. Chem. Chem. Phys., 2014, 16, 21673.

13 T. R. Willson, PhD thesis, The University of Surrey, 2018, available at, http://epubs.surrey.ac.uk/id/eprint/846392.

14 T. Sata, J. Membr. Sci., 2000, 167, 1.

15 (a) T. Yamaki, J. Tsukada, M. Asano, R. Katakai and M. Yoshida, J. Fuel Cell Sci. Technol., 2007, 4, 56; (b) J. Chen, M. Asano, T. Yamaki and M. Yoshida, J. Power Sources, 2006, 158, 69; (c) J. Chen, M. Asano, T. Yamaki and M. Yoshida, J. Appl. Polym. Sci., 2006, 100, 4565; (d) J. Chen, M. Asano, T. Yamaki and M. Yoshida, J. Membr. 
Sci., 2006, 269, 194; (e) M. Elomaa, S. Hietala, M. Paronen, N. Walsby, K. Jokela, R. Serimaa, M. Torkkeli, T. Lehtinen, G. Sundholm and F. Sundholm, J. Mater. Chem., 2000, 10, 2678; $(f)$ T. Lehtinen, G. Sundholm and F. Sundholm, $J$. Appl. Electrochem., 1999, 29, 677.

16 V. Sproll, T. J. Schmidt and L. Gubler, Polym. Int., 2016, 65, 174.

17 N. Brun, I. Youssef, M.-C. Chevrel, D. Chapron, C. Schrauwen, S. Hoppe, P. Bourson and A. Durand, J. Raman Spectrosc., 2013, 44, 909.

18 H. Ericson, T. Kallio, T. Lehtinen, B. Mattsson, G. Sundholm, F. Sundholm and P. Jacobsson, J. Electrochem. Soc., 2002, 149, A206.

19 C. R. Martins, F. Hallwass, Y. M. B. de Almeida and M.-A. Paoli, Annals of Magnetic Resonance, 2007, 6, 46.
20 E. Güler, Y. Zhang, M. Saakes and K. Nijmeijer, ChemSusChem, 2012, 5, 2262.

21 P. Długołęcki, K. Nijmeijer, S. Metz and M. Wessling, J. Membr. Sci., 2008, 319, 214.

22 J. G. Hong, B. Zhang, S. Glabman, N. Uzal, X. Dou, H. Zhang, X. Wei and Y. Chen, J. Membr. Sci., 2015, 486, 71.

23 (a) J. Moreno, S. Grasman, R. van Engelen and K. Nijmeijer, Environ. Sci. Technol., 2018, 52, 10856; (b) A. H. Avci, R. A. Tufa, E. Fontananova and G. di Profio, Energy, 2018, 165, 512; (c) H. Liu, H. Ren, Y. Zhao, J. Pan, A. Sotto, C. Gao, B. van der Bruggen and J. Shen, J. Membr. Sci., 2017, 543, 310.

24 https://www.gaiamembranes.com/, accessed 2019-04-24. 